\title{
Study on Water Injection Indicator Curve Model in Fractured Vuggy Carbonate Reservoir
}

\author{
Wang Yong $\mathbb{B}^{-}$, Jiang Hanqiao, and Li Junjian \\ State Key Laboratory of Petroleum Resources and Engineering, China University of Petroleum-Beijing, Beijing 102249, China \\ Correspondence should be addressed to Wang Yong; wycupb@gmail.com
}

Received 12 April 2021; Accepted 9 August 2021; Published 21 August 2021

Academic Editor: Judit Mádl-Szonyi

Copyright () 2021 Wang Yong et al. This is an open access article distributed under the Creative Commons Attribution License, which permits unrestricted use, distribution, and reproduction in any medium, provided the original work is properly cited.

\begin{abstract}
Fractures and cavities are very well developed in fractured vuggy carbonate reservoirs in Tahe Oilfield, showing obvious constant volume or approximate constant volume characteristics, and the development of karst vuggy reservoirs is characterized by strong randomness, locality, heterogeneity, and discontinuous development, which has a great impact on oilfield development effect. The application of conventional reservoir engineering methods in this kind of reservoir has many limitations. The traditional water injection indication curve is mainly based on a sandstone reservoir, ignoring the elastic energy of the water body in a reservoir and the combination relationship of fracture and cavity, which can not meet the needs of the carbonate reservoir. According to the principle of volume balance of constant volume body and considering the elastic energy of original formation water, a new model of improved water injection indication curve and the original water-oil ratio of carbonate reservoir is proposed, and the chart of water injection indication curve is established. Compared with other methods, this method has the advantages of low cost and accurate identification results. The calculated reservoir parameters such as single well-controlled reserves, wellcontrolled water volume, and original water-oil ratio have high reliability, and the chart is easy to use. The model is applied to the Yuejin block of Tahe Oilfield, and the results show that the improved model is consistent with the results of other test methods, such as high-precision seismic combined with fracture cavity carving technology, which indicates that the model has strong reliability.
\end{abstract}

\section{Introduction}

There have been many discussions on the characteristics and uses of the water injection indicator curve in the carbonate reservoir, but the theoretical research on the water injection indicator curve model in this kind of reservoir is relatively rare or has not formed a unified understanding [1-5]. To fully understand and utilize the data in the process of water injection in the carbonate reservoir, analyze the oil-water relationship in the reservoir, and correctly guide the implementation of the next working system and measures, the author takes the unsaturated carbonate reservoir as an example to study the establishment of reservoir water injection indicator curve model, the drawing of curve line, and its application, to provide the selection of water injection volume in the process of oil displacement by water injection, Therefore, the water injection indicator curve will play a better role in the development of carbonate reservoir in the future.
The carbonate reservoir is different from the sandstone reservoir. The calculation error of the conventional sandstone reservoir water injection indicator curve model is large [6-10]. Therefore, it is necessary to study and analyze the carbonate reservoir and reconstruct a new model that is consistent with the characteristics of the carbonate reservoir. In the process of water injection, there is little difference between the response of porous media and karst cave medium [10-13]. Therefore, the main types of carbonate reservoir are divided into single cave constant volume, multiple cave constant volumes, and fracture cavity constant volume (dual media). What is the constant volume refers to the constant volume of the karst cave. When water injection develops, the volume of reservoir fluid decreases with the increase of injected water volume, which is also called a constant volume reservoir [14-16].

$\mathrm{Ma}$ and Mei et al. derived the modified water injection indication curve considering that the elastic energy of 
original formation water in the fractured vuggy reservoir can not be ignored: (1) the theoretical model is not combined with the actual needs of the site; (2) the theoretical model ignores the calculation of the original water-oil ratio $R$ in the actual use process. In this case, the relative error can be reduced to 0 , which lacks practical use value $[17,18]$. Therefore, based on the previous experience and the principle of volume balance in cave constant volume body, a new model of water injection indication curve is derived. The expression of the original water-oil ratio $R$ is added into the new model to determine the volume of crude oil and formation water in the cave constant volume body more accurately.

\section{Establishment of Water Injection Indication Curve Model}

\subsection{Water Injection Indication Curve Model of Single Karst Cave and Constant Volume Body}

2.1.1. Model Derivation. Considering the elastic energy of the original formation water body, the volume change of the single cave constant volume is ignored. In other words, the volume of a single cave and constant volume $V_{\mathrm{p}}$ remains unchanged, as shown in Figure 1.

Under the original conditions, the original formation pressure is $P_{0}$, and the volume of a single karst cave is a constant

$$
V_{\mathrm{p}}=V_{\mathrm{oi}}+V_{\mathrm{wi}}
$$

After $W_{\mathrm{e}}$ volume of surface water is injected, the formation pressure rises to $P$,

$$
\begin{aligned}
V_{\mathrm{p}} & =V_{\mathrm{o}}+V_{\mathrm{w}}+W_{\mathrm{e}} \cdot B_{\mathrm{w}}, \\
C_{\mathrm{o}} & =\frac{1}{\Delta P} \cdot \frac{\Delta V_{\mathrm{o}}}{V_{\mathrm{o}}}, \\
\Delta V_{\mathrm{o}} & =V_{\mathrm{oi}}-V_{\mathrm{o}}=C_{\mathrm{o}} \cdot V_{\mathrm{oi}} \cdot \Delta P, \\
C_{\mathrm{w}} & =\frac{1}{\Delta P} \cdot \frac{\Delta V_{\mathrm{w}}}{V_{\mathrm{w}}}, \\
\Delta V_{\mathrm{w}} & =V_{\mathrm{wi}}-V_{\mathrm{w}}=C_{\mathrm{w}} \cdot V_{\mathrm{wi}} \cdot \Delta P, \\
V_{\mathrm{oi}}+V_{\mathrm{wi}} & =V_{\mathrm{o}}+V_{\mathrm{w}}+W_{\mathrm{e}} \cdot B_{\mathrm{w}}, \\
W_{\mathrm{e}} \cdot B_{\mathrm{w}} & =\Delta V_{\mathrm{o}}+\Delta V_{\mathrm{w}}=C_{\mathrm{o}} \cdot V_{\mathrm{oi}} \cdot \Delta P+C_{\mathrm{w}} \cdot V_{\mathrm{wi}} \cdot \Delta \mathrm{P}, \\
P & =P_{\mathrm{o}}+\frac{W_{\mathrm{e}} \cdot B_{\mathrm{w}}}{C_{\mathrm{o}} \cdot V_{\mathrm{oi}}+C_{\mathrm{w}} \cdot V_{\mathrm{wi}}} .
\end{aligned}
$$

The original water-oil ratio $R=V_{\mathrm{wi}} / V_{\mathrm{oi}}, V_{\mathrm{oi}}=N \cdot B_{\mathrm{oi}}$ :

$$
P=P_{\mathrm{o}}+\frac{W_{\mathrm{e}} \cdot B_{\mathrm{w}}}{N \cdot B_{\mathrm{oi}}\left(C_{\mathrm{o}}+R \cdot C_{\mathrm{w}}\right)} .
$$

From this, the water injection model of single volume is obtained.

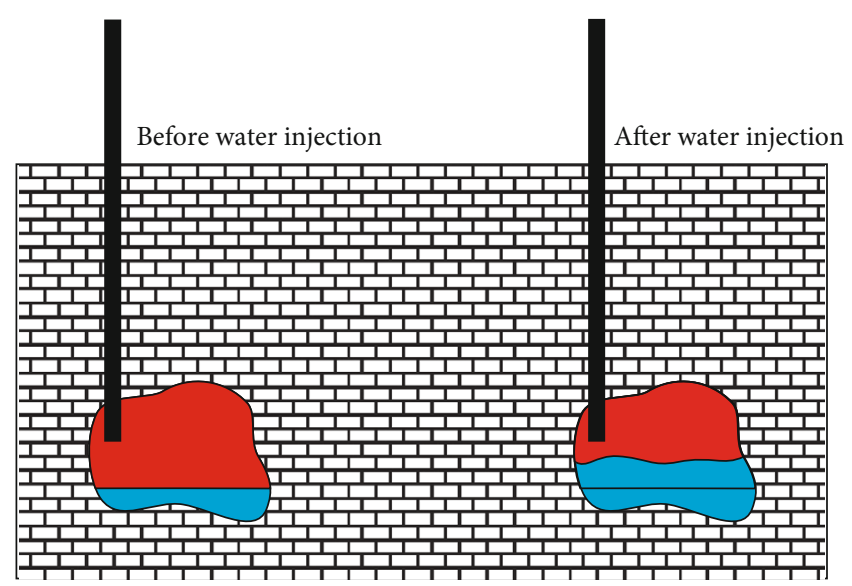

FIgURE 1: The injection indication curve model in single karst-cave constant volume.

Intercept $b=P_{0}$, reflecting the formation pressure before water injection:

Slope $K=B_{\mathrm{w}} /\left(N \cdot B_{\mathrm{oi}}\left(C_{\mathrm{o}}+R \cdot C_{\mathrm{w}}\right)\right)$; the smaller the slope, the larger the swept volume.

When the formation water body and injected water elastic energy is not taken into account, $R=0, B_{\mathrm{w}}=1$, substituting into equation (3), we can get

$$
P=P_{\mathrm{o}}+\frac{W_{\mathrm{e}}}{N \cdot B_{\mathrm{oi}} \cdot C_{\mathrm{o}}} .
$$

According to equations (3) and (4), the water injection indication curve under different driving energy is drawn, as shown in Figure 2.

2.1.2. Parameter Calculation. According to the water injection indicator curve model of single cave constant volume body and its characteristic analysis, the following parameters can be determined:

(1) Geological reserves:

$$
N=\frac{V_{\mathrm{oi}}}{B_{\mathrm{oi}}}=\frac{B_{\mathrm{w}}}{K \cdot B_{\mathrm{oi}}\left(C_{\mathrm{o}}+R \cdot C_{\mathrm{w}}\right)} .
$$

(2) Original water volume:

$$
V_{\mathrm{wi}}=R \cdot V_{\mathrm{oi}}=\frac{R \cdot B_{\mathrm{w}}}{K\left(C_{\mathrm{o}}+R \cdot C_{\mathrm{w}}\right)} .
$$

(3) Cave volume:

$$
V_{\mathrm{p}}=V_{\mathrm{oi}}+R \cdot V_{\mathrm{oi}}=(1+R) V_{\mathrm{oi}}=\frac{B_{\mathrm{w}}(1+R)}{K\left(C_{\mathrm{o}}+R \cdot C_{\mathrm{w}}\right)} .
$$




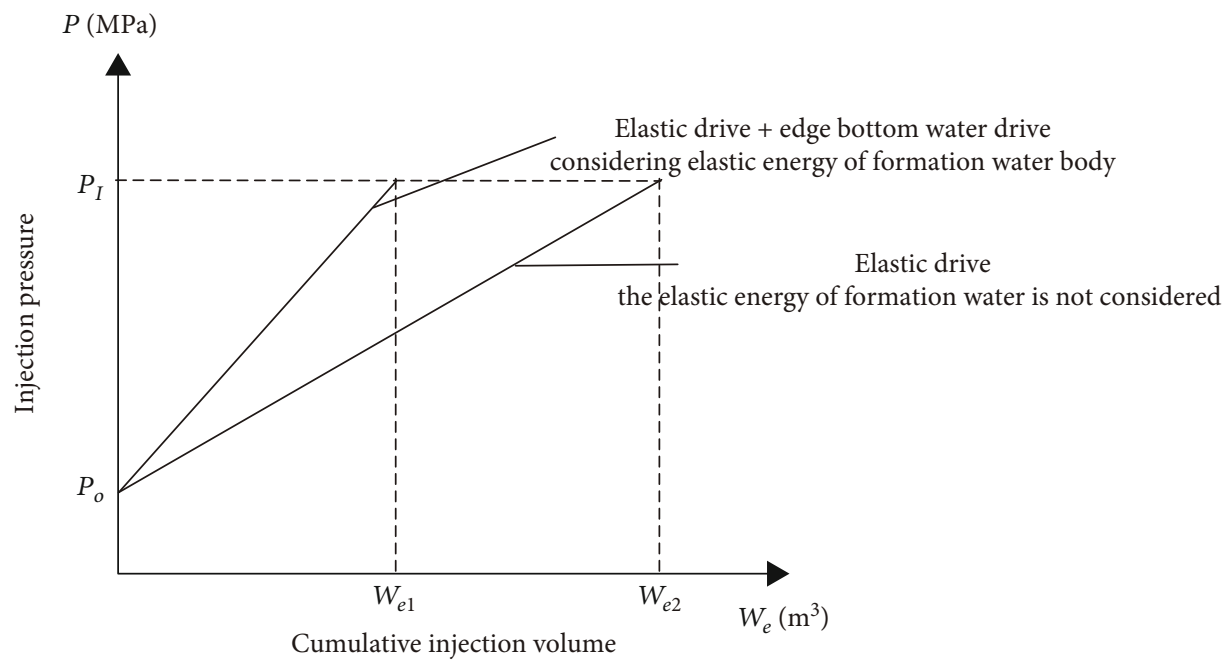

Figure 2: The injection indication curve in single karst-cave constant volume.

2.2. Water Injection indicator Curve Model of Multikarst Caves and Constant Volume. The multicave constant volume model is also one of the typical reservoir types of carbonate reservoirs. The author takes the double cave-constant volume model, as an example, and the multicave constant volume model is the same. Considering the energy of the water body, it is assumed that the fracture between the two caves only plays a role of diversion, and the cavern is the main reservoir, ignoring the reservoir performance of fractures, as shown in Figure 3.

2.2.1. Model Derivation. Set the volume of cave 1 and cave 2 as $V_{\mathrm{p} 1}$ and $V_{\mathrm{p} 2}$, respectively, and the water injection volume is $W_{\mathrm{e}}$. When the water injection volume is we1, cave 1 is full, cave 2 starts to inject, and the corresponding pressure when cave 1 is full is $P_{1}$. The results are as follows:

$$
\begin{aligned}
V_{\mathrm{p} 1} & =V_{\mathrm{oi} 1}+V_{\mathrm{wi} 1}, \\
V_{\mathrm{p} 2} & =V_{\mathrm{oi} 2}+V_{\mathrm{wi} 2}, \\
R_{1} & =\frac{V_{\mathrm{oi} 1}}{V_{\mathrm{wi}}}, \\
R_{2} & =\frac{V_{\mathrm{oi} 2}}{V_{\mathrm{wi} 2}},
\end{aligned}
$$

When $W_{\mathrm{e}}<W_{\mathrm{el}}$, it is a single cave constant volume model:

$$
P=P_{\mathrm{o}}+\frac{W_{\mathrm{e}} \cdot B_{\mathrm{w}}}{C_{\mathrm{o}} \cdot V_{\mathrm{oil}}+C_{\mathrm{w}} \cdot V_{\mathrm{wil}}}=P_{\mathrm{o}}+\frac{W_{\mathrm{e}} \cdot B_{\mathrm{w}}}{N_{1} \cdot B_{\mathrm{oi}}\left(C_{\mathrm{o}}+C_{\mathrm{w}} \cdot R\right)} .
$$

When $W_{\mathrm{e}}>W_{\mathrm{el}}$, it is a double cave constant volume model:

At this time, the water injection can be divided into two stages:

(1) When the pressure is $P_{1}$,

$$
P_{1}=P_{\mathrm{o}}+\frac{W_{\mathrm{el}} \cdot B_{\mathrm{w}}}{N_{1} \cdot B_{\mathrm{oi}}\left(C \mathrm{o}+C \mathrm{w} \cdot R_{1}\right)}
$$

(2) When the pressure is greater than $P_{1}, \Delta P=P-P_{1}$

$$
W_{\mathrm{e}}-W_{\mathrm{e} 1}=\Delta V_{\mathrm{o} 1}+\Delta V_{\mathrm{w} 1}+\Delta V_{\mathrm{o} 2}+\Delta \mathrm{V}_{\mathrm{w} 2},
$$

$$
\begin{aligned}
W_{\mathrm{e}}-W_{\mathrm{e} 1}= & C \mathrm{o} \cdot V_{\mathrm{oi} 1} \cdot \Delta P+C_{\mathrm{w}} \cdot V_{\text {wil }} \cdot \Delta P+C_{\mathrm{o}} \cdot V_{\mathrm{oi} 2} \cdot \Delta P \\
& +C_{\mathrm{w}} \cdot V_{\mathrm{wi} 2} \cdot \Delta P,
\end{aligned}
$$

$$
P=P_{1}+\frac{\left(W_{\mathrm{e}}-W_{\mathrm{e} 1}\right) \cdot B_{\mathrm{w}}}{C_{\mathrm{o}} \cdot V_{\mathrm{oil}}+C_{\mathrm{w}} \cdot V_{\text {wil }}+C_{\mathrm{o}} \cdot V_{\mathrm{oi} 2}+C_{\mathrm{w}} \cdot V_{\text {wi2 }}},
$$

$$
P=P_{1}+\frac{\left(W_{\mathrm{e}}-W_{\mathrm{e} 1}\right) \cdot B_{\mathrm{w}}}{N_{1} \cdot B_{\mathrm{oi}}\left(C_{\mathrm{o}}+C_{\mathrm{w}} \cdot R_{1}\right)+N_{2} \cdot B_{\mathrm{oi}}\left(C_{\mathrm{o}}+C_{\mathrm{w}} \cdot R_{2}\right)}
$$

By substituting equation (9) into equation (13), the

$$
\begin{aligned}
P= & P_{\mathrm{o}}+\frac{W_{\mathrm{el}} \cdot B_{\mathrm{w}}}{N_{1} \cdot B_{\mathrm{oi}}\left(C_{\mathrm{o}}+C_{\mathrm{w}} \cdot R_{1}\right)} \\
& +\frac{\left(W_{\mathrm{e}}-W_{\mathrm{e} 1}\right) \cdot B_{\mathrm{w}}}{N_{1} \cdot B_{\mathrm{oi}}\left(C_{\mathrm{o}}+C_{\mathrm{w}} \cdot R_{1}\right)+N_{2} \cdot B_{\mathrm{oi}}\left(C_{\mathrm{o}}+C_{\mathrm{w}} \cdot R_{2}\right)}
\end{aligned}
$$

Thus, the water injection indicator curve model of multikarst caves and constant volume body is obtained.

Intercept $b=P_{0}$, reflecting the formation pressure before water injection:

(1) Cave 1 slope: 


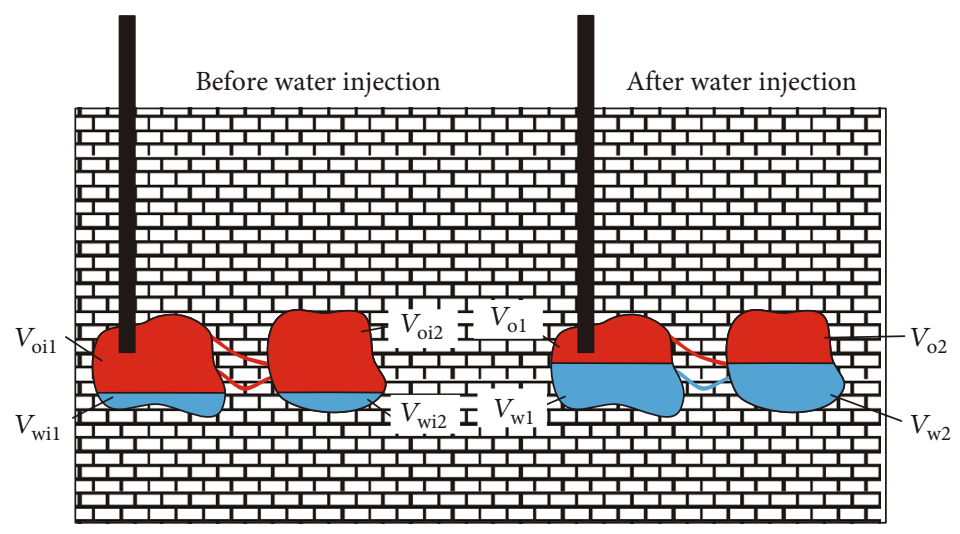

Figure 3: The injection indication curve model in multiple karst-cave constant volume.

$$
K_{1}=\frac{B_{\mathrm{w}}}{N_{1} \cdot B_{\mathrm{oi}}\left(C_{\mathrm{o}}+R_{1} \cdot C_{\mathrm{w}}\right)} .
$$

(2) Cave 2 slope:

$$
K_{2}=\frac{B_{\mathrm{w}}}{N_{1} \cdot \mathrm{B}_{\mathrm{oi}}\left(C_{\mathrm{o}}+C_{\mathrm{w}} \cdot R_{1}\right)+N_{2} \cdot B_{\mathrm{oi}}\left(C_{\mathrm{o}}+C_{\mathrm{w}} \cdot R_{2}\right)} .
$$

The smaller the slope is, the larger the swept volume is. Obviously, $K_{2}<K_{1}$, the water injection indicator curve should be shifted downward, and the migration amplitude is related to the volume of cave 2 .

When the formation water body and injected water elastic energy are not taken into account, substituting $R_{1}=$ $R_{2}=0, B_{\mathrm{w}}=1$ into equation (9) into (15), we can get the following:

When $W_{\mathrm{e}}<W_{\mathrm{e} 1}$, it is a single cave constant volume model:

$$
P=P_{\mathrm{o}}+\frac{W_{\mathrm{e}}}{N_{1} \cdot B_{\mathrm{oi}} \cdot C_{\mathrm{o}}} .
$$

When $W_{\mathrm{e}}>W_{\mathrm{e} 1}$, it is a multicave constant volume model:

$$
P=P_{\mathrm{o}}+\frac{W_{\mathrm{el}} \cdot B_{\mathrm{w}}}{N_{1} \cdot B_{\mathrm{oi}} \cdot C_{\mathrm{o}}}+\frac{W_{\mathrm{e}}-W_{\mathrm{e} 1}}{N_{1} \cdot B_{\mathrm{oi}} \cdot C_{\mathrm{o}}+N_{2} \cdot B_{\mathrm{oi}} \cdot C_{\mathrm{o}}} .
$$

According to equations (18) and (19), the water injection indicator curve of multikarst cave constant volume body is drawn, as shown in Figure 4.

2.2.2. Parameter Calculation. According to the water injection indicator curve model of single cave constant volume body and its characteristic analysis, the following parameters can be determined:

$$
N_{1}=\frac{V_{\mathrm{oil}}}{B_{\mathrm{oi}}}=\frac{B_{\mathrm{w}}}{K_{1} \cdot B_{\mathrm{oi}}\left(C_{\mathrm{o}}+R_{1} \cdot C_{\mathrm{w}}\right)}
$$

(2) The original water volume is

$$
V_{\text {wil }}=R_{1} \cdot V_{\text {oil }}=\frac{\mathrm{B}_{\mathrm{w}}}{K_{1}\left(C_{\mathrm{o}}+R_{1} \cdot C_{\mathrm{w}}\right)}
$$

(3) The total volume of cave 1 is

$$
V_{\mathrm{p} 1}=V_{\mathrm{oil}}+R_{1} \cdot V_{\mathrm{oil}}=\left(1+R_{1}\right) V_{\mathrm{oil}}=\frac{B_{\mathrm{w}}\left(1+R_{1}\right)}{K_{1}\left(C_{\mathrm{o}}+R_{1} \cdot C_{\mathrm{w}}\right)}
$$

(4) The geological reserves of karst cave 2 are

$$
N_{2}=\frac{V_{\mathrm{oi} 2}}{B_{\mathrm{oi}}}=\frac{B_{\mathrm{w}}-K_{2} \cdot N_{1} \cdot B_{\mathrm{oi}}\left(C_{\mathrm{o}}+C_{\mathrm{w}} \cdot R_{1}\right)}{K_{2} \cdot B_{\mathrm{oi}}\left(C_{\mathrm{o}}+C_{\mathrm{w}} \cdot R_{2}\right)}
$$

(5) The original water volume is

$$
V_{\text {wi2 }}=R_{2} \cdot V_{\text {oi } 2}=\frac{B_{\mathrm{w}}-K_{2} \cdot N_{1} \cdot B_{\text {oi }}\left(C_{\mathrm{o}}+C_{\mathrm{w}} \cdot R_{1}\right)}{K_{2}\left(C_{\mathrm{o}}+C_{\mathrm{w}} \cdot R_{2}\right)}
$$

(1) The geological reserves of cave 1 are

(6) The total volume of cave 2 is 


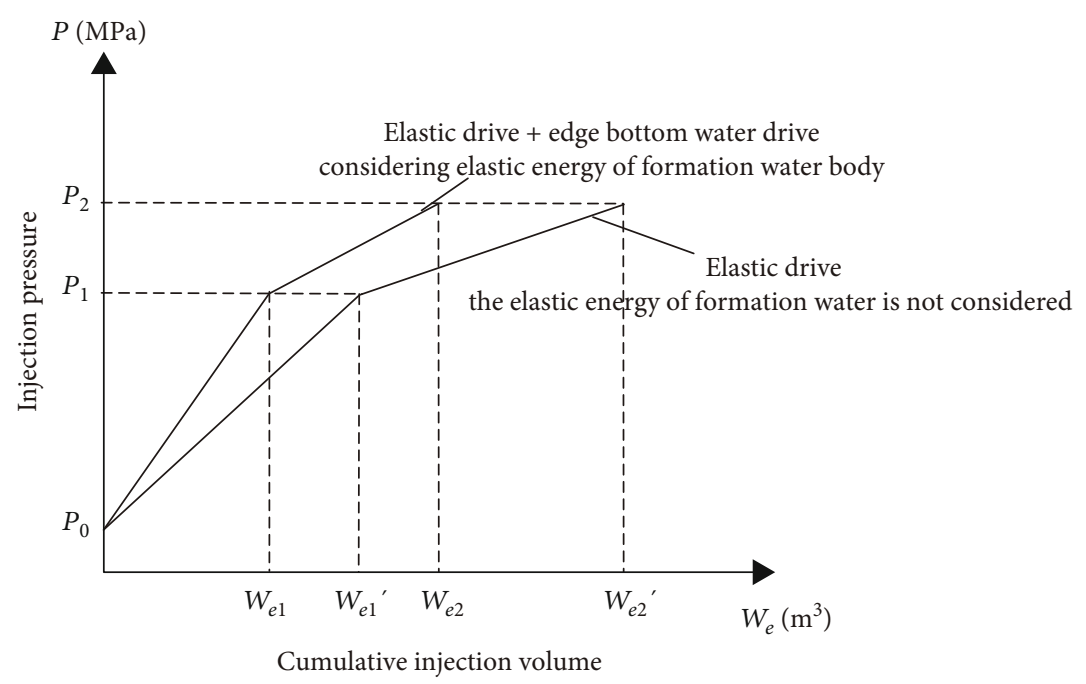

FIGURE 4: The injection indication curve in multiple karst-cave constant volume.

$V_{\mathrm{p} 2}=\left(1+R_{2}\right) V_{\mathrm{oi} 2}=\left(1+R_{2}\right) \frac{B_{\mathrm{w}}-K_{2} \cdot N_{1} \cdot B_{\mathrm{oi}}\left(C_{\mathrm{o}}+C_{\mathrm{w}} \cdot R_{1}\right)}{K_{2}\left(C_{\mathrm{o}}+C_{\mathrm{w}} \cdot R_{2}\right)}$

\subsection{Water Injection Indication Curve Model of Fracture Cavity Constant Volume Body}

2.3.1. Model Derivation. For fractured vuggy reservoirs with constant volume, fractures can be used as both seepage channels and reservoirs to store oil and gas. Therefore, it is divided into two parts: the fractured reservoir and karst cave reservoir. At this time, after a certain amount of water is injected into the reservoir, the reservoir pressure rises from the original formation pressure $P_{\mathrm{o}}$ to the current formation pressure $P$, and the increasing value of reservoir pressure is $\Delta P=P-P_{\mathrm{o}}$, as shown in Figure 5.

(1) Fractured Reservoir. Define the volume of the fracture unit is $V_{\mathrm{pf}}$, the volume of crude oil is $V_{\text {of }}$ and the volume of formation water is $V_{\mathrm{wf}}$; then $V_{\mathrm{pf}}=V_{\mathrm{of}}+V_{\mathrm{wf}}$ :

The original fluid in the fracture is compressed due to the increase of pressure, and the compression amount is the volume of injected water in the fracture, viz $W_{\text {if }}$.

$$
\begin{aligned}
\Delta V_{\mathrm{of}}+\Delta V_{\mathrm{wf}} & =W_{\text {if }} \times B_{\mathrm{w}}, \\
\Delta V_{\mathrm{of}} & =C_{\mathrm{o}} \times V_{\text {of }} \times \Delta P, \\
\Delta V_{\mathrm{wf}} & =C_{\mathrm{w}} \times V_{\mathrm{wf}} \times \Delta P .
\end{aligned}
$$

By combining formulas (26), (27), and (28), we can get

$$
C_{\mathrm{o}} \times V_{\text {of }} \times \Delta P+C_{\mathrm{w}} \times V_{\mathrm{wf}} \times \Delta P=W_{\text {if }} \times B_{\mathrm{w}} .
$$

(2) Cavernous Reservoir. The volume of cave unit is $V_{\mathrm{pr}}$, the volume of crude oil is $V_{\text {or }}$, and the volume of formation water is $V_{\mathrm{wr}}$; then $V_{\mathrm{pr}}=V_{\mathrm{or}}+V_{\mathrm{wr}}$ :
The original fluid in the cave is compressed due to the increase of pressure, and the compression amount is the volume of injected water in the cavern in the reservoir, i.e. $W_{\text {ir }}$.

$$
\begin{aligned}
\Delta V_{\text {or }}+\Delta V_{\mathrm{wr}} & =W_{\mathrm{ir}} \times B_{\mathrm{w}}, \\
\Delta V_{\mathrm{or}} & =C_{\mathrm{o}} \times V_{\text {or }} \times \Delta P, \\
\Delta V_{\mathrm{wr}} & =C_{\mathrm{w}} \times V_{\mathrm{wr}} \times \Delta P .
\end{aligned}
$$

By combining equations (30), (31), and (32), we can get

$$
C_{\mathrm{o}} \times V_{\text {or }} \times \Delta P+C_{\mathrm{w}} \times V_{\mathrm{wr}} \times \Delta P=W_{\mathrm{ir}} \times B_{\mathrm{w}} .
$$

(3) Fracture Cavity Type Constant Volume Body. For fractured vuggy reservoir with constant volume, because fractures not only are seepage channels but also have certain reservoir performance, it is considered that the pressure in fracture vuggy constant volume reservoir is the synchronous response. If the ratio of fracture volume to cave volume is set as $\alpha$, the water-oil ratio in the fracture is $R_{1}$, and the water-oil ratio in karst cave is $R_{2}$, then

$$
\begin{aligned}
\alpha & =\frac{V_{\mathrm{pf}}}{V_{\mathrm{pr}}}, \\
R_{1} & =\frac{V_{\mathrm{wf}}}{V_{\mathrm{of}}}, \\
R_{2} & =\frac{V_{\mathrm{wr}}}{V_{\mathrm{or}}}, \\
V_{\mathrm{of}} & =\frac{1}{\left(1+R_{1}\right) V_{\mathrm{pf}}}=\frac{\alpha}{\left(1+R_{1}\right) V_{\mathrm{pr}}},
\end{aligned}
$$




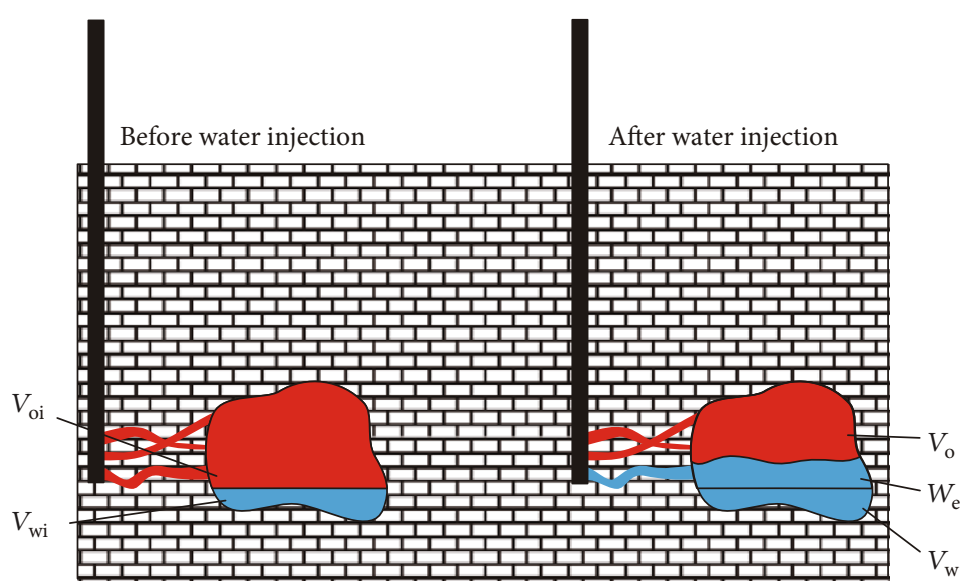

FIGURE 5: The injection indication curve model in fractured-vuggy karst-cave constant volume.

$$
\begin{gathered}
V_{\mathrm{wf}}=\frac{R_{1}}{\left(1+R_{1}\right) V_{\mathrm{pf}}}=\frac{\alpha \cdot R_{1}}{\left(1+R_{1}\right) V_{\mathrm{pr}}}, \\
V_{\mathrm{or}}=\frac{1}{\left(1+R_{2}\right) V_{\mathrm{pr}}}, \\
V_{\mathrm{wr}}=\frac{R_{2}}{\left(1+R_{2}\right) V_{\mathrm{pr}}} .
\end{gathered}
$$$$
C_{\mathrm{o}} \times\left(V_{\mathrm{of}}+V_{\text {or }}\right) \times \Delta P+C_{\mathrm{w}} \times\left(V_{\mathrm{wf}}+V_{\mathrm{wr}}\right) \times \Delta P=W_{\mathrm{i}} \times B_{\mathrm{w}}
$$

Substituting equations (34)-(40) into equation (42), we can get

$$
P=P_{\mathrm{o}}+\frac{W_{\mathrm{e}} \cdot B_{\mathrm{w}}}{\left[C_{\mathrm{o}} \cdot\left(\left(\alpha /\left(1+R_{1}\right)\right)+\left(1 /\left(1+R_{2}\right)\right)\right)+C_{\mathrm{w}} \cdot\left(\left(\left(\alpha \cdot R_{1}\right) /\left(1+R_{1}\right)\right)+\left(R_{2} /\left(1+R_{2}\right)\right)\right)\right] \cdot V_{\mathrm{pr}}} .
$$

Substituting $V_{\mathrm{pr}}=\operatorname{Vor}\left(1+R_{2}\right)$ into equation (43), we get

$$
P=P_{\mathrm{o}}+\frac{W_{\mathrm{i}} \cdot B_{\mathrm{w}}}{\left\{C_{\mathrm{o}} \cdot\left[\left(\left(\alpha\left(1+R_{2}\right)\right) /\left(1+R_{1}\right)\right)+1\right]+C_{\mathrm{w}} \cdot\left[\left(\left(\alpha R_{1} \cdot\left(1+R_{2}\right)\right) /\left(1+R_{1}\right)\right)+R_{2}\right]\right\} \cdot V_{\mathrm{or}}} .
$$

Thus, the water injection indicator curve model of fracture cavity constant volume body is obtained.
Intercept $b=P_{0}$, reflecting the formation pressure before water injection:

The slope is

$$
K=\frac{B_{\mathrm{w}}}{\left\{C_{\mathrm{o}} \cdot\left[\left(\left(\alpha\left(1+R_{2}\right)\right) /\left(1+R_{1}\right)\right)+1\right]+C_{\mathrm{w}} \cdot\left[\left(\left(\alpha R_{1} \cdot\left(1+R_{2}\right)\right) /\left(1+R_{1}\right)\right)+R_{2}\right]\right\} \cdot V_{\mathrm{or}}} .
$$


The smaller the slope, the larger the swept volume.

In the process of reservoir development, fracture as a seepage channel, once water is cut, it will inevitably cause rapid water breakthrough and even violent water flooding of the well. Therefore, $R_{1}=0$ is substituted into equation (44), and

$$
P=P_{\mathrm{o}}+\frac{W_{\mathrm{i}} \cdot \mathrm{B}_{\mathrm{w}}}{\left\{C_{\mathrm{o}}\left[\alpha\left(1+R_{2}\right)+1\right]+C_{\mathrm{w}} \cdot R_{2}\right\} \cdot V_{\text {or }}} .
$$

When the fracture is not developed and can not be used as a reservoir, $\alpha=0$, it is a single karst cave constant volume model, which can be substituted into equation (46)

$$
P=P_{\mathrm{o}}+\frac{W_{\mathrm{i}} \cdot B_{\mathrm{w}}}{\left(C_{\mathrm{o}}+C_{\mathrm{w}} \cdot R_{2}\right) \cdot V_{\mathrm{or}}}
$$

Obviously, because fractures contribute part of the reservoir, the slope decreases; that is, the larger $\alpha$ is, the smaller the slope of the water injection indicator curve is.

Thus, the fracture cavity type constant volume injection indicator curve is drawn, as shown in Figure 6.

2.3.2. Parameter Calculation. The following are the parameter calculations:

(1) Geological reserves in fractures:

$$
N_{\mathrm{f}}=\frac{V_{\mathrm{of}}}{B_{\mathrm{oi}}}=\frac{1}{1+\mathrm{R}_{1}} \cdot V_{\mathrm{pf}}=\frac{\alpha \cdot B_{\mathrm{w}}}{\left\{C_{\mathrm{o}} \cdot\left(\alpha+\left(\left(1+R_{1}\right) /\left(1+R_{2}\right)\right)\right)+C_{\mathrm{w}} \cdot\left[\alpha \cdot R_{1}+\left(\left(R_{2} \cdot\left(1+R_{1}\right)\right) /\left(1+R_{2}\right)\right)\right]\right\} \cdot K \cdot B_{\mathrm{oi}}} .
$$

(2) Volume of water in fracture:

$$
V_{\mathrm{wf}}=\frac{R_{1}}{1+R_{1}} \cdot \mathrm{V}_{\mathrm{pf}}=\frac{\alpha \cdot R_{1} \cdot B_{\mathrm{w}}}{\left\{C_{\mathrm{o}} \cdot\left(\alpha+\left(\left(1+R_{1}\right) /\left(1+R_{2}\right)\right)\right)+C_{\mathrm{w}} \cdot\left[\alpha \cdot R_{1}+\left(\left(R_{2} \cdot\left(1+R_{1}\right)\right) /\left(1+R_{2}\right)\right)\right]\right\} \cdot K} .
$$

(3) Crack volume:

$$
V_{\mathrm{pf}}=\alpha \cdot V_{\mathrm{pr}}=\frac{\alpha \cdot B_{\mathrm{w}}}{\left[C_{\mathrm{o}} \cdot\left(\left(\alpha /\left(1+R_{1}\right)\right)+\left(1 /\left(1+R_{2}\right)\right)\right)+C_{\mathrm{w}} \cdot\left(\left(\left(\alpha \cdot R_{1}\right) /\left(1+R_{1}\right)\right)+\left(R_{2} /\left(1+R_{2}\right)\right)\right)\right] \cdot K} .
$$

(4) Geological reserves in karst cave:

$$
N_{\mathrm{r}}=\frac{V_{\mathrm{or}}}{B_{\mathrm{oi}}}=\frac{B_{\mathrm{w}}}{\left\{C_{\mathrm{o}} \cdot\left[\left(\left(\alpha\left(1+R_{2}\right)\right) /\left(1+R_{1}\right)\right)+1\right]+C_{\mathrm{w}} \cdot\left[\left(\left(\alpha \cdot R_{1} \cdot\left(1+R_{2}\right)\right) /\left(1+R_{1}\right)\right)+R_{2}\right]\right\} \cdot K \cdot B_{\mathrm{oi}}} .
$$

(5) Volume of water in karst cave:

$$
V_{\mathrm{wr}}=R_{2} \cdot V_{\mathrm{or}}=\frac{R_{2} \cdot B_{\mathrm{w}}}{\left\{C_{\mathrm{o}} \cdot\left[\left(\left(\alpha\left(1+R_{2}\right)\right) /\left(1+R_{1}\right)\right)+1\right]+C_{\mathrm{w}} \cdot\left[\left(\left(\alpha \cdot R_{1} \cdot\left(1+R_{2}\right)\right) /\left(1+R_{1}\right)\right)+R_{2}\right]\right\} \cdot K} .
$$

(6) Cave volume:

$$
V_{\mathrm{pr}}=\left(1+R_{2}\right) \cdot V_{\text {or }}=\frac{B_{\mathrm{w}}}{\left[C_{\mathrm{o}} \cdot\left(\left(\alpha /\left(1+R_{1}\right)\right)+\left(1 /\left(1+R_{2}\right)\right)\right)+C_{\mathrm{w}} \cdot\left(\left(\left(\alpha \cdot R_{2}\right) /\left(1+R_{2}\right)\right)+\left(R_{2} /\left(1+R_{2}\right)\right)\right)\right] \cdot K} .
$$




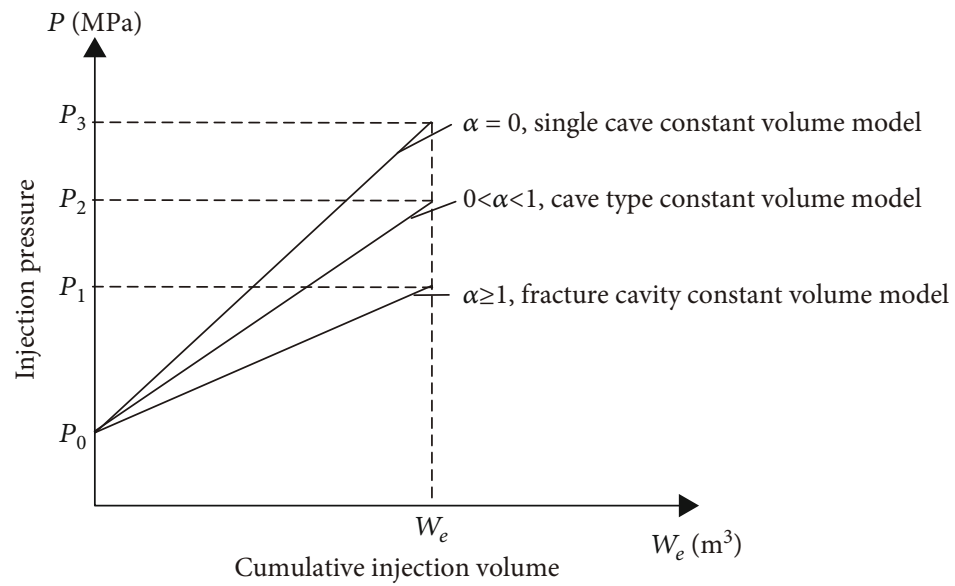

FIGURE 6: Water injection indication curve of fracture cavity-type constant volume body.

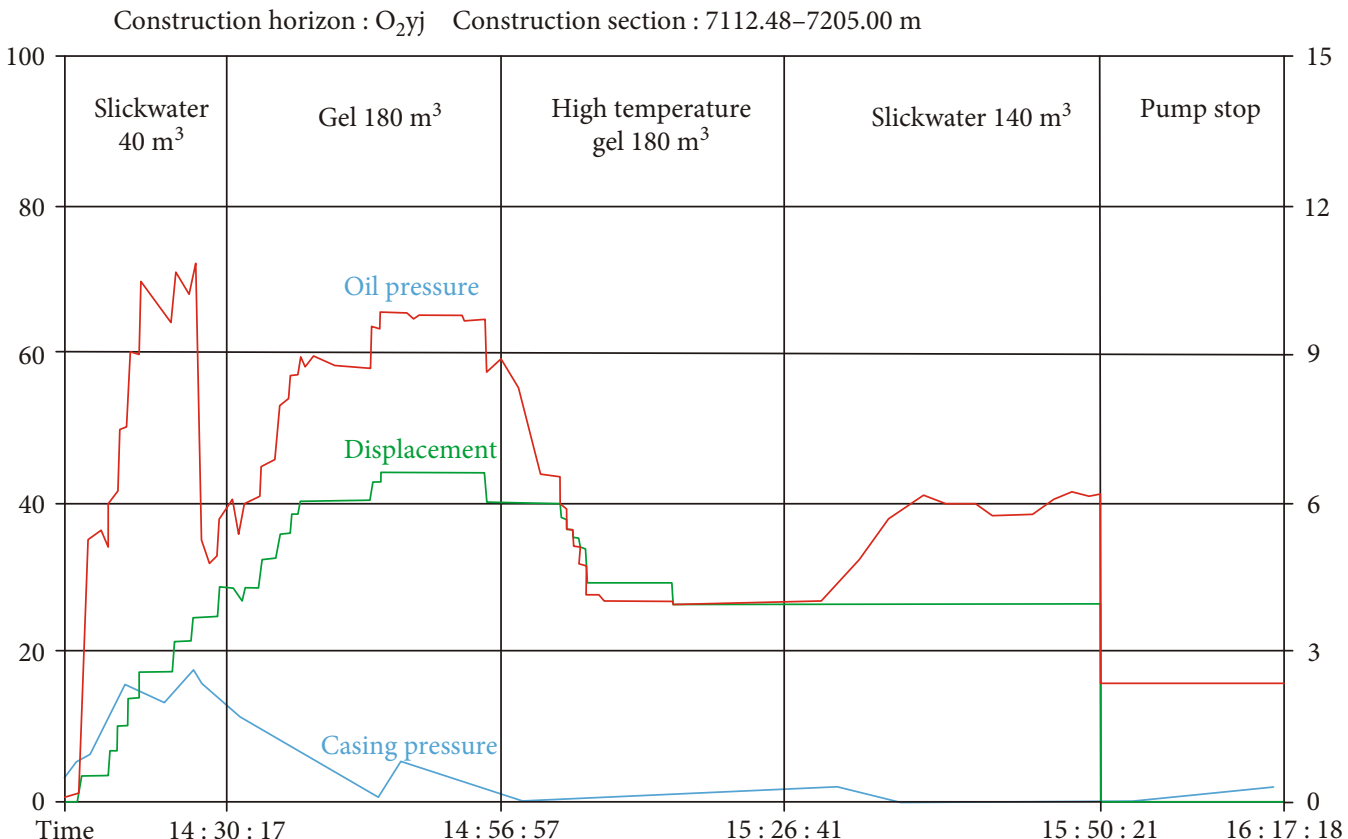

Figure 7: Acid fracturing construction curve.

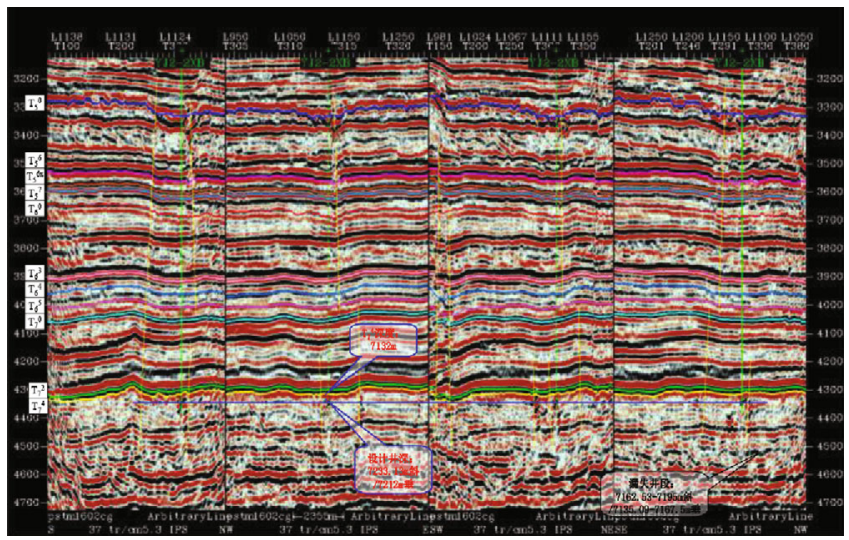

Figure 8: Seismic profile of well Y1-X.

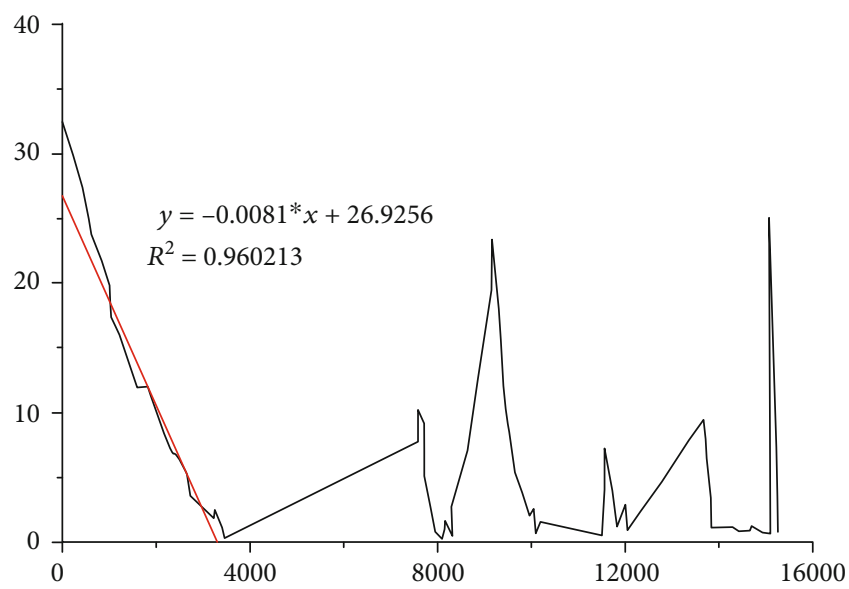

FIGURE 9: Y1-x energy indicating curve. 


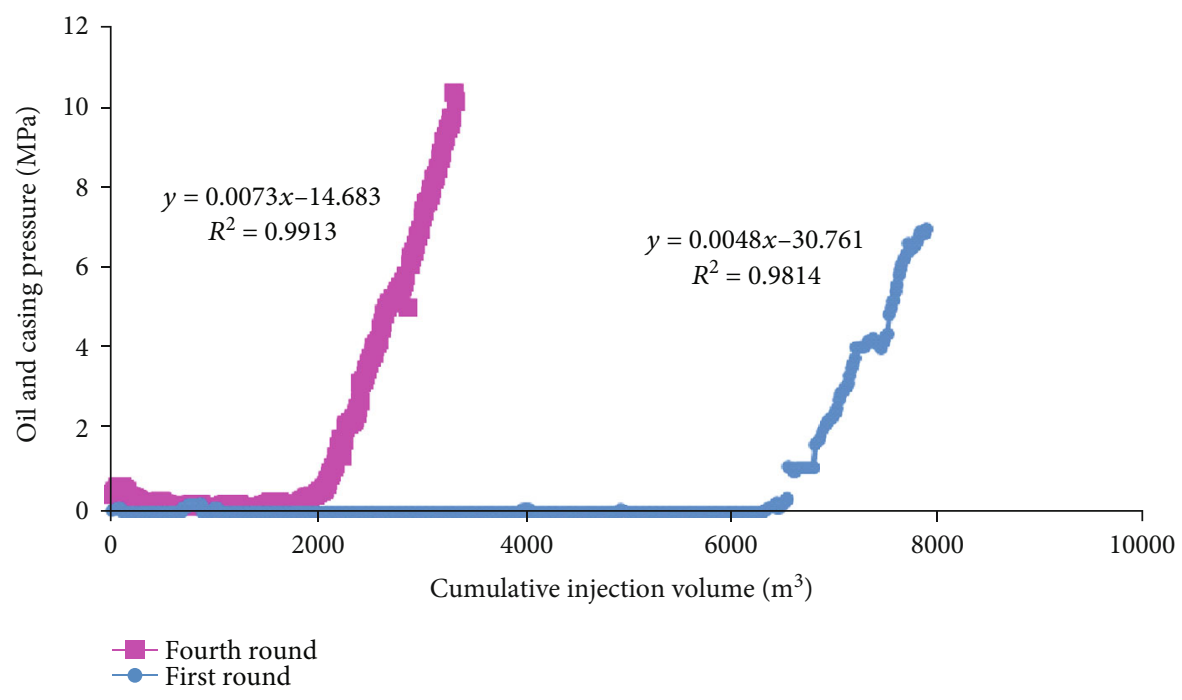

FIGURE 10: Y1-x First and fourth round injection indicating curve.

2.4. Derivation of Original Water Oil Ratio R. The original water-oil ratio $R$ is not only the core of the model but also the key parameter to solve the model. In general, it is necessary to make a relationship curve fitting through field simulation to get $R$. To facilitate the field application, the author made a simplified model and solved the expression of $R$.

2.4.1. Solving $R$ by Multiple Water Injection $(n \geq 2)$. In a constant volume reservoir, the well control reserves of the multicave constant volume reservoir can be obtained from the first round of water injection indicator curve, and then, the difference between the remaining oil of the well and the remaining oil of the previous round is calculated as the volume of crude oil produced in this round.

$\Delta V_{\mathrm{o}^{n}}=V_{\mathrm{o}^{n-1}}-\mathrm{V}_{\mathrm{o}^{n}}=\frac{B_{\mathrm{w}}}{K_{n-1}\left(C_{\mathrm{o}}+R \cdot C_{\mathrm{w}}\right)}-\frac{B_{\mathrm{w}}}{K_{n}\left(C_{\mathrm{o}}+R \cdot C_{\mathrm{w}}\right)}$,

where $n$ is the water injection round $(n \geq 2)$.

For the convenience of field application, let $\Delta V_{\mathrm{o}^{n-1}}=$ $N_{\mathrm{p}^{n-1}}$ and $N_{\mathrm{p}^{n-1}}$ be the actual volume of crude oil produced between two water injection cycles.

$$
\begin{gathered}
\frac{B_{\mathrm{w}}}{K_{n-1}\left(C_{\mathrm{o}}+R \cdot C_{\mathrm{w}}\right)}-\frac{B_{\mathrm{w}}}{K_{n}\left(C_{\mathrm{o}}+R \cdot C_{\mathrm{w}}\right)}=N_{\mathrm{p}^{n-1}}, \\
R=\left[\frac{B_{\mathrm{w}} \cdot\left(K_{n}-K_{n-1}\right)}{N_{\mathrm{p}^{n-1}} \cdot K_{n-1} \cdot K_{n}}-C_{\mathrm{o}}\right] \cdot \frac{1}{C_{\mathrm{w}}} .
\end{gathered}
$$

2.4.2. Using Energy Indicating Curve to Solve R. In the process of field application, it often occurs that the water injection rounds are not enough or some water injection indicating curves cannot be used. Therefore, the energy index curve is used to replace the water injection indication

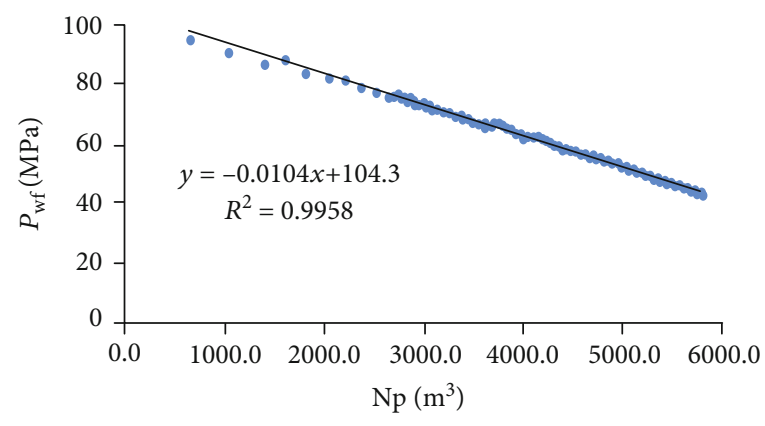

FIGURE 11: Energy indicating curve of well Y2-X.

curve. The slope of the energy indicating curve is $K_{0}$, which is taken as the slope of the first water injection indicating curve and can be substituted into formula (56) to obtain $R$.

$$
R=\left[\frac{B_{\mathrm{w}} \cdot\left(K_{n}-K_{0}\right)}{N_{\mathrm{po}^{n-1}} \cdot K_{0} \cdot K_{n}}-C_{\mathrm{o}}\right] \cdot \frac{1}{C_{\mathrm{w}}}
$$

At this time, the $B_{\mathrm{oi}} V_{\mathrm{oi}}$ obtained is the well-controlled reserves of the cavern constant volume body, and $R \cdot V_{\mathrm{oi}}$ is the original water volume of the reservoir.

The following are the instructions:

$V_{\mathrm{o}^{n}}, V_{\mathrm{w}^{n}}$ are the volume of remaining oil and bottom water in the formation during the $n$th round of water injection.

$\mathrm{V}_{\mathrm{o}^{n-1}} \mathrm{~V}_{\mathrm{o}^{n-1}}$ is the volume of oil produced between two rounds.

$\mathrm{V}_{\mathrm{w}^{n-1}}-\mathrm{V}_{\mathrm{w}^{n}}$ is the volume of injected water to volume of produced water between two rounds.

Therefore, $R$ is a variable quantity in the production process, but it can be regarded as a constant value on the premise that there are not many water injection rounds and the difference between the volume of oil produced and the volume of injected water and produced water is small. When 


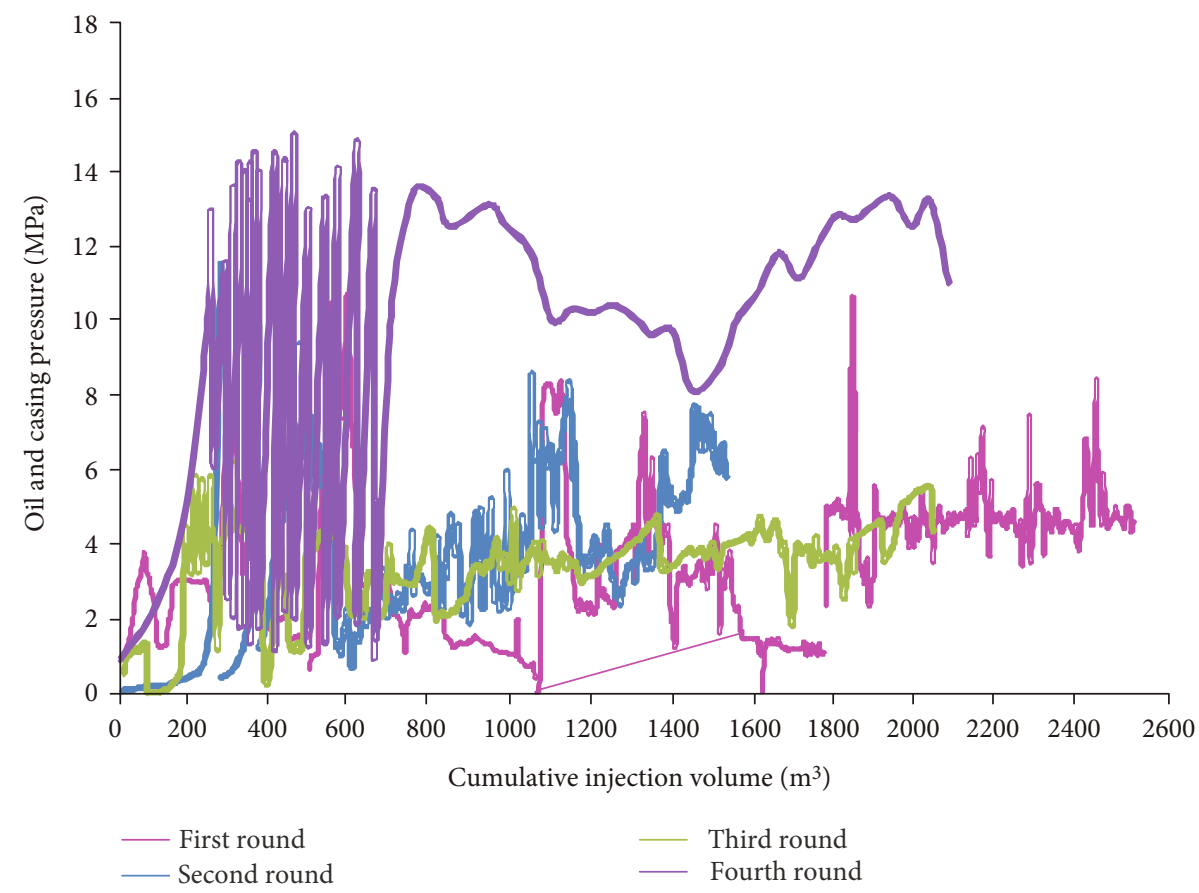

FIGURE 12: Water injection indication curve of well Y2-x in the first four rounds.

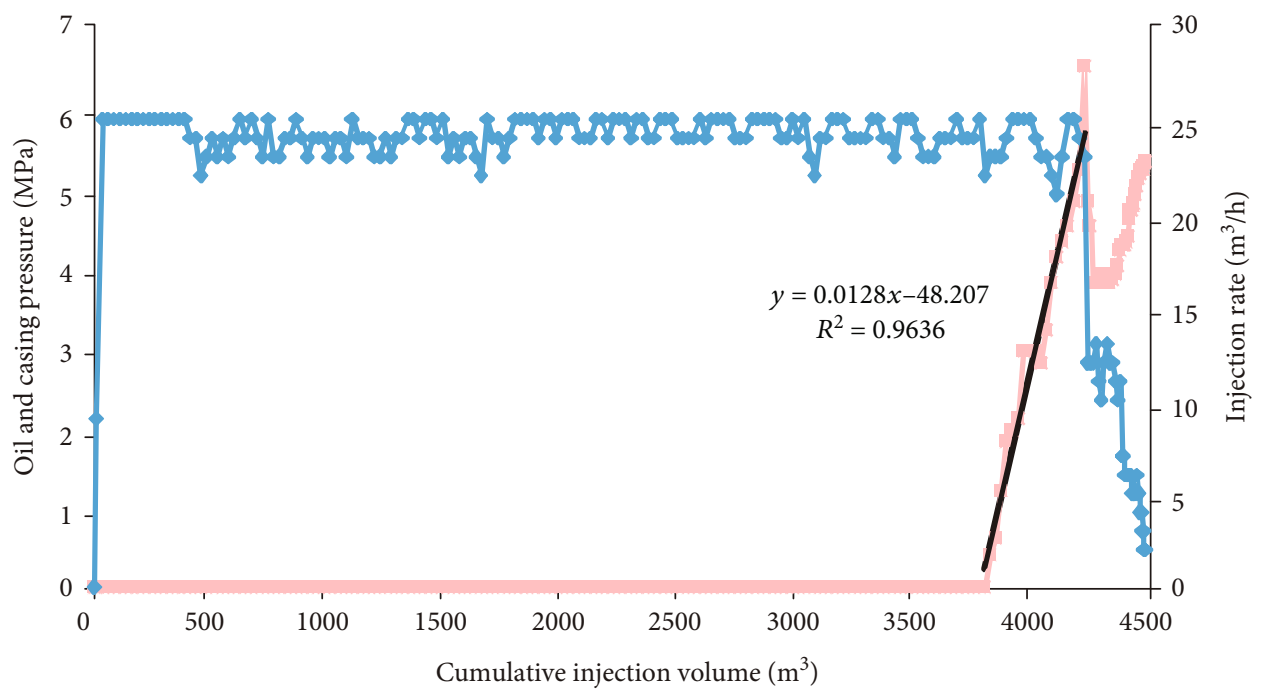

Casing pressure (MPa)

Injection rate $\left(\mathrm{m}^{3} / \mathrm{h}\right)$

FIGURE 13: Fifth round water injection indicator curve of well Y2-x.

TABLE 1: Comparisons of the calculated results for the reserves.

\begin{tabular}{|c|c|c|c|c|c|c|c|c|c|c|c|}
\hline \multirow{2}{*}{ Well name } & \multicolumn{3}{|c|}{ Volume of solid carving } & \multirow{2}{*}{ Volume factor } & \multirow{2}{*}{ Crude oil density $\left(\mathrm{t} / \mathrm{m}^{3}\right)$} & \multicolumn{3}{|c|}{ Oil saturation } & \multicolumn{2}{|c|}{$\begin{array}{l}\text { Single well } \\
\text { reserves (t) }\end{array}$} & \multirow{2}{*}{ Error/\% } \\
\hline & Cave & Pore & Fracture & & & Cave & Pore & Fracture & Carving & New & \\
\hline YJ1-X & 186136 & 38467 & 9531 & 2.171 & 0.795 & 0.814 & 0.664 & 0.9 & 67978 & 62275 & 8.39 \\
\hline YJ2-X & 118089 & 41126 & 7282 & 2.171 & 0.795 & 0.814 & 0.664 & 0.9 & 47600 & 41994 & 11.78 \\
\hline
\end{tabular}


the output and water injection increase in the middle and later stages, $R$ will also increase correspondingly, but the $R$ value of two adjacent times has little change, so this formula can also be used.

\section{Field Application and Analysis of New Model}

The well control reserves and water volume of key wells in the Yuejin block are predicted by using the new model of water injection indication curve and the original water-oil ratio formula established, and the predicted results are compared with the actual production results $[19,20]$.

3.1. Well Y1-x. The completion depth of Y1-x well is $7205 \mathrm{~m}$ (slant)/7185.68 $\mathrm{m}$ (vertical), and the bushing elevation is $82.5 \mathrm{~m}$ (slant)/82.2 $\mathrm{m}$ (vertical), and acid fracturing is completed. It can be clearly seen from the acid fracturing operation curve (Figure 7) that the acidizing effectively communicated with the reservoir. The pressure drop was measured after the pump was stopped for $20 \mathrm{~min}$. The oil pressure rose from 15.7 to $15.9 \mathrm{MPa}$, and the acidizing effect was good. Combined with seismic data (Figure 8) and energy indicating curve (Figure 9), the seismic time migration section shows that Y1-X well has "string bead" reflection characteristics under $\mathrm{T}_{7}{ }^{4}$ seismic reflection wave, and the energy indicator curve shows that the well has obvious constant volume characteristics, so it can be judged that the well is a karst cave constant volume body.

The well has accumulated 4 rounds of water injection, and the first and fourth rounds of water injection indication curves are as follows (Figure 10). During this period, the cumulative oil production is $13305 \mathrm{t}$, and the surface crude oil density of the Yuejin block is $0.795 \mathrm{~g} / \mathrm{cm}^{3}$, the volume coefficient is 1.617 , the compressibility coefficient of formation crude oil is $15 \times 10^{-4} \mathrm{MPa}^{-1}$, and the compressibility coefficient of formation water is $4 \times 10^{-4} \mathrm{MPa}^{-1}$ $\left(K_{0}=0.0048, K_{1}=0.0073\right)$. Substituting the above data into formula (56), $R=2.9$ is obtained. The original oil-bearing volume of the well is $78333 \mathrm{~m}^{3}$, the remaining reserves are $61597 \mathrm{~m}^{3}$, the total well control reserves are $62275 \mathrm{t}$, and the remaining reserves are $48970 \mathrm{t}$.

3.2. Well Y2-x. The drilling depth of well Y2-x is $7091.73 \mathrm{~m}$, and the bushing elevation is $23.73 \mathrm{~m}$. The lost circulation during drilling is $3160.9 \mathrm{~m}^{3}$, showing a cavernous reservoir. The energy indicator curve (Figure 11) shows that the well has obvious constant volume characteristics, so it belongs to a typical karst cave constant volume reservoir. During the first four rounds of water injection, the water injection indicator curve (Figure 12) shows that the data correlation is poor, and the data is scattered, reflecting the obvious sand burial characteristics. At the same time, there is sand burial history in the early production process of the well, so the sand washing acidification is carried out, and the fifth round water injection indicator curve (Figure 13) after acidification is available.

After the fifth round of water injection, the produced crude oil is $4900 \mathrm{t}$, the surface crude oil density is $0.795 \mathrm{~g} / \mathrm{cm}^{3}$, the volume coefficient is 1.617 , the formation crude oil compression coefficient is $15 \times 10^{-4} \mathrm{MPa}^{-1}$, and the formation water compression coefficient is $4 \times 10^{-4} \mathrm{MPa}^{-1}$ $\left(K_{0}=0.0104, K_{1}=0.0128\right)$. By substituting the above data into formula (57), $R=0.8$ is obtained. The original oilbearing volume of the well is $52822 \mathrm{~m}^{3}$, the remaining reserves are $42918 \mathrm{~m}^{3}$, the total well control reserves are $41994 \mathrm{t}$, and the remaining reserves are $37094 \mathrm{t}$.

3.3. New Model Validation. Dong Xianzhang and others used the volume method to check the calculation results when calculating the well-controlled reserves [21-25]. The essence of high-precision seismic combined with fracture cavity carving technology is also a volume method, and it is more accurate than other methods in the calculation of oil well control area and reservoir height [26-29]. Therefore, the author uses this method to test the calculation results of the new model. The calculation results are shown in Table 1. Obviously, the geological reserves calculated by highprecision earthquake combined with fracture cavity carving technology are very close to the results calculated by the author, and the error is controlled at about $10 \%$.

\section{Conclusions}

(1) Through the study of carbonate reservoir, it can be divided into single cave constant volume, multicave constant volume, and fracture cavity constant volume (double porosity medium). On this basis, the water injection indication curve model under different reservoir conditions is given. The water injection indicator curve is drawn by using the established new model, and the corresponding geological reserves, original water volume, and reservoir volume corresponding to the model are solved, which provides the basic theoretical basis for the formulation of the working system and measures of carbonate reservoir and water injection for oil displacement in the next step

(2) For the convenience of field application, the original water-oil ratio and its solution formula are derived by using multiple rounds of water injection and energy indicating curve, which can more accurately calculate the well control reserves and original water volume of karst cave constant volume reservoir. Based on the field data, this paper demonstrates the accuracy of the new model and the original wateroil ratio formula and, on this basis, rechecks and verifies the well control reserves of the internal wells in the block, which provides the basis for the determination of the next working system, the formulation of water injection, and other related measures. This method has been applied to the Tahe Oilfield of China

(3) This model is derived from the principle of volume balance of constant volume body. It applies to the cavern constant volume reservoir with edge and bottom water and without edge and bottom water and the cave constant volume body with water content 
rising in the reservoir in the middle and late stage of water injection development. It has good adaptability to approximate constant volume reservoir and low permeability carbonate reservoir

\section{Abbreviations}

$P$

$P_{0}:$

$P_{1}, P_{2}, P_{3}$

$\triangle P:$

$V_{\mathrm{p}}:$

$V_{\mathrm{p} 1}$ :

$V_{\mathrm{p} 2}:$

$V_{\mathrm{pf}}:$

$V_{\mathrm{pr}}:$

$W_{\mathrm{e}}$ :

$V_{\text {oi }}$ :

$V_{\text {wi: }}$ :

$V_{\text {oil }}$ :

$V_{\text {wil }}$ :

$V_{\text {oi2 }}$ :

$V_{\text {wi2 }}$ :

$V_{\text {of }}$ :

The total volume of frac-
$V_{\text {wf }}$ :

$V_{\text {or }}$ :

Formation pressure $(\mathrm{MPa})$

Original formation pres-

sure $(\mathrm{MPa})$

Different injection pres-

sures $(\mathrm{MPa})$

Production pressure dif- $\quad V_{\mathrm{o}}$ :

ference $(\mathrm{MPa})$

Total volume of single cave and constant volume $\left(\mathrm{m}^{3}\right)$

Total volume of cave 1

with multiple caves and constant volume $\left(\mathrm{m}^{3}\right)$

Total volume of cave 2

with multiple caves and constant volume $\left(\mathrm{m}^{3}\right)$

Total volume of fractures

in fracture cavity type constant volume body $\left(\mathrm{m}^{3}\right)$ ture cavern with constant volume $\left(\mathrm{m}^{3}\right)$

Surface water injection volume $\left(\mathrm{m}^{3}\right)$

The volume of crude oil in single cave constant volume formation $\left(\mathrm{m}^{3}\right)$

The volume of formation water in a single karst cave with constant volume $\left(\mathrm{m}^{3}\right)$

The volume of crude oil in karst cave 1 with multiple caves and constant volume $\left(\mathrm{m}^{3}\right)$

The volume of layer water in cave 1 with multiple caves and constant volume $\left(\mathrm{m}^{3}\right)$

The volume of crude oil in the inner layer of cave 2 with multiple caves and constant volume $\left(\mathrm{m}^{3}\right)$

The volume of formation water in cave 2 with multiple caves and constant volume $\left(\mathrm{m}^{3}\right)$

The volume of crude oil in fractured vuggy reservoir with constant volume $\left(\mathrm{m}^{3}\right)$
$V_{\mathrm{wr}}$ :

$V_{\mathrm{w}}:$

$W_{\text {if }}$ :

$W_{\text {ir }}:$

$\alpha:$

$C_{\mathrm{o}}$ :

$C_{\mathrm{w}}$ :

$\Delta V_{\mathrm{o}}, \Delta V_{\mathrm{o} 1}, \Delta V_{\mathrm{o} 2}, \Delta V_{\mathrm{of}}, \Delta V_{\text {or }}$ :

$\Delta V_{\mathrm{w}}, \Delta V_{\mathrm{w} 1}, \Delta V_{\mathrm{w} 2}, \Delta V_{\mathrm{wf}}, \Delta V_{\mathrm{wr}}:$

$B_{\mathrm{w}}:$

$B_{\mathrm{o}}$ :

$B_{\mathrm{oi}}$ :

$R, R_{1}, R_{2}$

$N, N_{1}, N_{2}, N_{\mathrm{f}}, N_{\mathrm{r}}$ :
The volume of formation water in fractured vuggy reservoir with constant volume $\left(\mathrm{m}^{3}\right)$

The volume of crude oil in fractured vuggy cavern reservoir with constant volume $\left(\mathrm{m}^{3}\right)$

The volume of formation water in fractured vuggy reservoir with constant volume $\left(\mathrm{m}^{3}\right)$

When the pressure is $P$, the volume of formation crude oil in a single cave constant volume body $0\left(\mathrm{~m}^{3}\right)$

When the pressure is $P$, the volume of formation water in a single cave constant volume body $\left(\mathrm{m}^{3}\right)$ When the pressure increases from $P_{0}$ to $P$, the amount of water compression in the fracture increases $\left(\mathrm{m}^{3}\right)$

When the pressure increases from $P_{0}$ to $P$, the amount of water compression in the cave will decrease $\left(\mathrm{m}^{3}\right)$

The ratio of fracture volume to cave volume When the pressure is $P$, the compressibility coefficient of formation crude oil is $\left(\mathrm{MPa}^{-1}\right)$

When the pressure is $P$, the compressibility coefficient of formation water is $\left(\mathrm{MPa}^{-1}\right)$

Pressure rise $\Delta P$, the amount of formation crude oil compression $\left(\mathrm{m}^{3}\right)$

Pressure rise $\Delta P$, formation water compression $\left(\mathrm{m}^{3}\right)$ When the pressure is $P$, the volume coefficient of formation water is $\left(\mathrm{m}^{3} / \mathrm{m}^{3}\right)$

When the pressure is $P$, the volume coefficient of formation crude oil is $\left(\mathrm{m}^{3} / \mathrm{m}^{3}\right)$ When the pressure is $P_{0}$, the volume coefficient of formation crude oil is 0 $\left(\mathrm{m}^{3} / \mathrm{m}^{3}\right)$

Water oil ratio $\left(\mathrm{m}^{3} / \mathrm{m}^{3}\right)$ Geological reserves $\left(\mathrm{m}^{3}\right)$ 
$b$ :

$K, K_{1}, K_{2}$ :
Intercept of water injection indication curve (f) Slope of water injection indication curve (f).

\section{Data Availability}

The data used to support the findings of this study are included within the article.

\section{Conflicts of Interest}

The authors declare that they have no conflicts of interest.

\section{Acknowledgments}

The authors would like to acknowledge the National Major Science and Technology Projects of China (CN) (Grant No. 2017ZX05009004) and the National Natural Science Foundation of China (Grant No. 51974331) for their financial support.

\section{References}

[1] J. Williams-Kovacs, C. R. Clarkson, and M. Nobakht, "Impact of material balance equation selection on rate-transient analysis of shale gas," in Paper presented at the SPE Annual Technical Conference and Exhibition, San Antonio, Texas, USA, 2012.

[2] T. K. Guo, S. Tang, S. Liu et al., "Physical simulation of hydraulic fracturing of large-sized tight sandstone outcrops," SPE Journal, vol. 26, no. 1, pp. 372-393, 2021.

[3] L. Chuanliang, "Production index curves of reservoir," Xinjiang Petroleum Geology, vol. 22, no. 4, pp. 333-334, 2001.

[4] F. Liu, J. M. Mendel, and A. M. Nejad, "Forecasting injector/producer relationships from production and injection rates using an extended Kalman filter," Spe Journal, vol. 14, no. 4, pp. 653-664, 2009.

[5] A. A. Yousef, P. H. Gentil, J. L. Jensen, and L. W. Lake, “A capacitance model to infer interwell connectivity from production and injection rate fluctuations," in Paper presented at the SPE Annual Technical Conference and Exhibition, Dallas, Texas, 2005.

[6] G. R. Jerauld, "Timing of miscible hydrocarbon gas injection after waterflooding," in Paper presented at the SPE/DOE Improved Oil Recovery Symposium, Tulsa, Oklahoma, 2000.

[7] J. K. Larsen, N. Bech, and A. Winter, "Three phase immiscible WAG injection: micromodel experiments and network models," in Paper presented at the SPE/DOE Improved Oil Recovery Symposium, Tulsa, Oklahoma, 2000.

[8] L. Aimin, Study of Reservoir Engineering Methods for Fractured-Vuggy Carbonate Reservoirs, Tahe Oilfield as an Example, [Ph.D. Thesis], China University of Petroleum, 2007.

[9] X. Yang, J. Tongwen, and F. Jilei, "Study of dynamic analytic method on fractured-vuggy carbonate reservoir," Petroleum Geology and Recovery Efficiency, vol. 19, no. 5, pp. 97-99, 2012.

[10] L. I. Yang, "The theory and method for development of carbonate fractured-cavity reservoirs in Tahe oilfield," Acta Petrolei Sinica, vol. 34, no. 1, pp. 115-121, 2013.

[11] Z. Wu, W. Hu, X. Song, Q. Ran, and J. Gan, "Numerical simulation on low-permeability reservoir with abundant natural micro-fractures," Acta Petrolei Sinica, vol. 30, no. 5, pp. $727-$ 730, 2009, 734.

[12] Z. Songqing, L. Zhongchun, and L. Qiu, "Evaluation of injected water utilization for fractured-vuggy reservoirs in Tahe oilfield," Xinjiang Petroleum Geology, vol. 38, no. 4, pp. 452-454, 2017.

[13] L. I. Peng, L. I. Pengcheng, W. A. Wenhuan, X. I. Jing, J. I. Yuwei, and L. I. Baozhu, "Establishment and application of a new combined solution model for water cut prediction," Xinjiang Petroleum Geology, vol. 38, no. 3, pp. 342-346, 2017.

[14] L. I. Xiaobo, R. O. Yuanshuai, and L. I. Xueli, "Failure characteristics and influencing factors analysis on water injection for oil wells in fractured-vuggy reservoir," Petroleum Geology and Recovery Efficiency, vol. 21, no. 1, pp. 59-62, 2014.

[15] Z. Dawei, Z. Zhaoying, and L. Zhenyu, "Pattern and analysis of flooding indication curves in Toutai oil field of Daqing," Journal of Daqing Petroleum Institute, vol. 26, no. 4, pp. 26-27, 2002.

[16] J. Yonghong, L. Anguo, J. Hui, T. Jing, and H. Lijuan, “Application of water flood index curve in carbonate reservoirs," Reservoir Evaluation and Development, vol. 3, no. 4, pp. 30-34, 2013.

[17] M. Shengwen, C. Xiaofan, Leping, T. Chao, and Y. Hu, "The new improved theory model of water flood index curve in fractured-vuggy carbonate reservoirs," Journal of Yangtze University (natural), vol. 12, no. 29, pp. 57-62, 2015.

[18] M. Xun, Study of Failure Characteristics on Water Injection for Oil Wells in Fractured-Vuggy Carbonate Reservoirs, Southwest Petroleum University, 2015.

[19] Y. W. He, S. Q. Cheng, Z. Sun, Z. Chai, and Z. H. Rui, "Improving oil recovery through fracture injection and production of multiple fractured horizontal wells," Journal of Energy Resources Technology, vol. 142, no. 5, article 053002, 2020.

[20] L. Ping, T. Chao, D. Zhimin et al., The Waterflood Indicating Curve Interpretation Model of Carbonate Fractured-Vuggy Reservoirs, 2017, Sichun: CN106837273A.

[21] L. Chuanliang and K. Xiangyan, "Study on the determination of productivity index and formation pressure of oil wells," Journal of Southwest Petroleum Institute, vol. 22, no. 2, pp. 40-42, 2000.

[22] C. Zhihai, C. Tielong, and L. Changhong, "A new approach to producing reserve calculation of fractured-vuggy carbonate rock reservoirs," Oil \& Gas Geology, vol. 28, no. 3, pp. 315319, 2007, 328.

[23] L. Ping, L. Dongchen, D. Zhimin et al., The Waterflood Indicating Curve Interpretation Model of Double Cavern in Carbonate Reservoirs, 2017, Sichun: CN106837273A.

[24] Z. Ling, H. Qingyu, and Z. Li, “Application of reserves estimation methods to fractured-vuggy carbonate reservoir," Petroleum Geology and Recovery Efficiency, vol. 19, no. 1, pp. 2427, 2012.

[25] E. H. Luo, Y. L. Hu, L. Wang, and J. He, “Analysis of production decline curves in naturally vuggy and fractured carbonate reservoir with low permeability media," Journal of Daqing Petroleum Institute, vol. 36, no. 2, pp. 86-90, 2012.

[26] W. Zhou, H. Deng, Y. Shan, Y. Yang, and H. Wang, "Experiment research on open and closed pressure of fault (fracture)," Acta Petrolei Sinica, vol. 29, no. 2, pp. 277-283, 2008.

[27] G. A. Wenjun, H. A. Wei, S. H. Han, W. E. Liyan, W. E. Lingxiang, and Z. H. Dengqiao, "Improvement of percolation 
theory on Arps production decline equation in water flooding oilfield," Xinjiang Petroleum Geology, vol. 38, no. 3, pp. 314318, 2017.

[28] T. H. Ahmed, A. Centilmen, and B. P. Roux, "A generalized material balance equation for coalbed methane reservoirs," in Paper presented at the SPE Annual Technical Conference and Exhibition, San Antonio, Texas, USA, January 2006.

[29] R. F. Yang, J. Q. Zhang, H. Chen, R. Z. Jiang, Z. Sun, and Z. H. Rui, "The injectivity variation prediction model for water flooding oilfields sustainable development," Energy, vol. 189, p. $116317,2019$. 